\title{
Atypical Sleep and Postoperative Delirium in the Cardiothoracic Surgical Intensive Care Unit: A Pilot Prospective Study
}

This article was published in the following Dove Press journal: Nature and Science of Sleep

\author{
Qiong Chen' \\ Yanchun Peng ${ }^{2}$ \\ Yanjuan Lin $^{3}$ \\ Sailan $\mathrm{Li}^{2}$ \\ Xizhen Huang ${ }^{2}$ \\ Liang-Wan Chen ${ }^{2}$ \\ 'Department of Nursing, Fujian Medical \\ University, Fuzhou, Fujian, People's \\ Republic of China; ${ }^{2}$ Department of \\ Cardiac Surgery, Union Hospital, Fujian \\ Medical University, Fuzhou, Fujian, \\ People's Republic of China; ${ }^{3}$ Department \\ of Nursing, Union Hospital, Fujian \\ Medical University, Fuzhou, Fujian, \\ People's Republic of China
}

Correspondence: Yanjuan Lin

Department of Nursing, Union Hospital, Fujian Medical University, No. 29 Xinquan Road, Fuzhou, 35000I Fujian Province, People's Republic of China

Tel +86 59|862 I858।

Fax +8683344034

Email fjxhyjl@I63.com

Liang-Wan Chen

Department of Cardiac Surgery, Union Hospital, Fujian Medical University,

Fuzhou, Fujian 35000I, People's Republic of China

Tel +8659|862|858|

$\mathrm{Fax}+8659183301393$

Email chenliangwan@tom.com
Purpose: Postoperative delirium (POD) is a very common and serious neurological complication in patients admitted to the cardiothoracic surgical intensive care unit (CSICU). We aimed to identify a novel potential sleep-based marker for POD and investigate the relevance between atypical sleep and POD.

Patients and Methods: This was a prospective, observational study of patients admitted to the CSICU between December 2019 and February 2020 at our center. Sleep characteristics from 21:00 on postoperative day 1 to 07:00 on postoperative day 2 were assessed using polysomnography (PSG). POD from the end of PSG monitoring until postoperative day 5 was evaluated using the Confusion Assessment Method for the Intensive Care Unit.

Results: This analysis included 20 patients admitted to the CSICU. The incidence of atypical sleep was $45.0 \%$. Compared to patients without delirium, those with delirium had less delta power, less percentage REM sleep, and a higher proportion of atypical sleep and REM sleep loss $(P<0.05)$.

Conclusion: The presence of atypical sleep and the absence of REM sleep were associated with POD in patients admitted to the CSICU.

Keywords: postoperative delirium, intensive care unit, atypical sleep, cardiac surgery

\section{Introduction}

Postoperative delirium (POD), is a common acute disturbance of consciousness occurring postoperatively among $11.5-39.0 \%$ of the patients admitted to the cardiothoracic surgical intensive care unit (CSICU), it is associated with prolonged hospital stay, poor outcomes, and increased health costs and mortality. ${ }^{1-5}$ Hence, identifying risk factors for POD is important. Current research shows that POD after cardiac surgery results from a combination of several factors, including advanced age, pre-existing cognitive impairment, previous psychiatric conditions, cerebrovascular disease, mechanical ventilation time, atrial fibrillation, and so forth. ${ }^{6,7}$ However, sleep disturbances, common among CSICU patients, could be a potential risk factor for POD. ${ }^{8}$

Most recent studies have only considered the association between delirium and normal sleep characteristics but not abnormal sleep characteristics. Normal sleep consists of 3 stages: WAKE, non-rapid eye movement (NREM) sleep (further divided into stages N1, N2, and N3), and rapid eye movement (REM) sleep. These can be identified using polysomnography (PSG). ${ }^{9}$ However, these typical sleep characteristics are often absent in patients admitted to the intensive care unit. 
Atypical sleep is an abnormal sleep subtype, characterized by loss of N2 stage markers (K-complexes and sleep spindles). ${ }^{10}$ The incidence of atypical sleep has been reported to be $28-50 \%{ }^{11-14}$ among awake or lightly sedated patients and $60-85 \%{ }^{10,15}$ among deeply sedated patients.

Only limited data exist regarding the association between atypical sleep and delirium, and the causality remains unclear. Previous studies indicate that delirium occurs in $44 \%$ of patients with atypical sleep as compared to $18 \%$ of patients without atypical sleep; however, whether atypical sleep occurs before delirium onset remains unclear. ${ }^{11}$ According to a study assessing sleep among 14 patients with mechanical ventilation, typical sleep features were only recognized in 1 patient without delirium. ${ }^{16}$ Another study reported no significant difference in the incidence of delirium during the PSG period between atypical and typical sleep. ${ }^{12}$ Although the cited studies were important, they did not definitively establish the association between atypical sleep and delirium primarily because these could not establish the sequence of delirium and atypical sleep. Hence, studies assessing the association between atypical sleep and delirium through a rigorous experimental design are lacking.

In this pilot study, we conducted PSG monitoring on the first postoperative night after cardiac surgery using cardiopulmonary bypass (CPB) and assessed delirium daily after PSG monitoring until postoperative day 5 to test the hypothesis that atypical sleep occurs before the onset of and is associated with delirium.

\section{Materials and Methods Design and Setting}

We conducted a pilot prospective study between December 2019 and February 2020 at the CSICU of our hospital. The study was approved by the Ethics Committee of our hospital and is registered at http://www.chictr.org.cn (ChiCTR1900023094).

We enrolled 23 patients aged $\geq 18$ years and undergoing cardiac surgery using CPB. Patients with the following conditions were excluded: (1) history or current diagnosis of mental illness or neurological disorders; (2) alcoholism (defined using the Alcohol Use Disorders Identification Test Consumption score $\geq 4$ in men and $\geq 3$ in women); ${ }^{17}$ (3) sleep disturbance (defined as a STOP-Bang score of $\geq 3$ ); ${ }^{18}$ (4) self-reported use of anticonvulsants, antidepressants, and neuroleptics 48 hours before the study; (5) contraindications for PSG, including infection, recent trauma, and head or neck surgery; (6) PSG monitoring time $\leq 7 \mathrm{~h}$ for various reasons (eg, wire loss or equipment failure); (7) delirium onset after the surgery till the end of monitoring; (8) inability to use the Confusion Assessment Method for the Intensive Care Unit (CAM-ICU) to confirm delirium or non-delirium (the Richmond AgitationSedation Scale $[$ RASS $\leq-4]) .{ }^{19,20}$

\section{Sleep Assessment}

A portable 52-channel sleep monitor (BMC Polypro, Beijing) was used for sleep monitoring. Electrode placement conformed to the "International 10-20" System. ${ }^{21}$ Electrodes were placed by a trained technician and included the following: 6 electroencephalogram (EEG) channels ( 2 frontal channels: F3-M2, F4-M1; 2 central channels: C3-M2, C4-M1; and 2 occipital channels: O1M2, O2-M1), 2 electrooculogram (E1, E2), and 2 electromyograms $\left(\mathrm{EMG}^{+}-\mathrm{EMG}^{-}\right)$. PSG was started at $21: 00$ on postoperative day 1 and was continuously performed until 07:00 on the next day (07:00, morning nursing; $21: 00$, end of visiting). All records, every 30-second epoch, were scored by a trained sleep technologist and reviewed by 2 sleep medicine physicians. The sleep technologist and sleep medicine physicians were blinded to patient group assignment during the study. If PSG observations conformed with the standard sleep stages, it was scored according to the 2007 American Academy of Sleep Medicine Manual for the Scoring of Sleep and Associated Events. If some epochs of PSG could not be scored using the standard criteria but were consistent with the description of atypical sleep, ${ }^{13,15}$ it was scored as atypical sleep.

For each EEG data set, we selected 100 minutes from a period with minimal care intervention (02:00-03:40); the spectral analysis of the delta $(0.5-3.9 \mathrm{~Hz})$, theta $(4.0-7.9$ $\mathrm{Hz})$, alpha $(8.0-13.0 \mathrm{~Hz})$, and beta $(13.1-30.0 \mathrm{~Hz})$ bands was performed using fast Fourier transformation of each 4-s epoch. The spectral power estimates were averaged across 6 EEG channels (F3-M2, F4-M1, C3-M2, C4-M1, $\mathrm{O} 1-\mathrm{M} 2$, and $\mathrm{O} 2-\mathrm{M} 1)$.

\section{Delirium Assessment}

POD was defined as delirium lasting from the end of PSG monitoring till postoperative day 5 , ensuring that delirium occurred after sleep monitoring. Patients were screened for delirium from the end of PSG monitoring until postoperative day 5 by trained nurses using RASS and 
Table I Sleep Characteristics of CSICU Patients

\begin{tabular}{|l|l|}
\hline & All Patients (n=20) \\
\hline Total recording time (min), mean (SD) & $506.42 \pm 55 . I I$ \\
Total sleep time (min), mean (SD) & $235.62 \pm 83.24$ \\
Sleep efficiency (\%), mean (SD) & $47.7 \pm 18.6$ \\
Stage NI sleep (\%), mean (SD) & $14.0 \pm 7.3$ \\
Stage N2 sleep (\%), mean (SD) & $29.3 \pm 20.4$ \\
Stage N3 sleep (\%), median (IQR) & $0.5(0,3.3)$ \\
REM sleep (\%), median (IQR) & $0(0,2.9)$ \\
\hline
\end{tabular}

Abbreviations: REM, rapid eye movement; SD, standard deviation; IQR, interquartile range.

CAM-ICU. ${ }^{19,20}$ To ensure that the sleep data were recorded before delirium and to minimize the effect of the assessment process on patients' sleep at night, patients were screened for delirium at 08:00, 14:00, and 20:00 every day. If patients presented any clinical evidence of delirium (such as agitation or illusion, as observed by the nurses) at other times (including entire sleep monitoring period), they were additionally screened by nurses using RASS and CAM-ICU.

\section{Clinical Data Collection}

Patients' sociodemographic characteristics, preoperative status, intraoperative variables, and relevant postoperative data were collected (Table 1). As analgesia and sedation may promote delirium, ${ }^{22,23}$ we also collected analgesia and sedation use information pre- and post-operatively till the end of PSG. Analgesics used were morphine, fentanyl, and dezocine, and sedatives used were dexmedetomidine, midazolam, and chlorpromazine.

\section{Statistical Analysis}

Patients were divided into the delirium and non-delirium groups based on whether they developed POD. Continuous variables were presented as mean \pm standard deviation (SD; normally distributed data) or medians and interquartile ranges (non-normally distributed data; $25-75 \%$ quartiles), and categorical variables were presented as numbers and percentages. The chi-square or Fisher exact test was used to compare qualitative data, as applicable, and the Student $t$ or Mann-Whitney $U$-test was used to compare quantitative data, as applicable. SPSS software (version 17.0) was used for data statistical analysis. $P<0.05$ was considered statistically significant.

\section{Results}

Of the 23 patients, 1 was excluded because of delirium onset before the end of PSG monitoring, 2 were excluded because of PSG monitoring lasting $\leq 7 \mathrm{~h}$ (caused by wire disconnection). Of the 20 CSICU patients, 9(45.0\%) had atypical sleep (atypical stages 1-3) per the Watson classification. ${ }^{15}$ The total atypical sleep duration was $4396 \mathrm{~min}$. A representative EEG of a patient with atypical sleep is shown in Figures 1, and 2 shows the percentage distribution of the sleep stages. Table 1 summarizes the sleep characteristics of all patients.

Figure 3 shows the distribution of POD. No significant differences existed between the groups in baseline characteristics including sociodemographic, preoperative, intraoperative, and postoperative variables (Table 2).

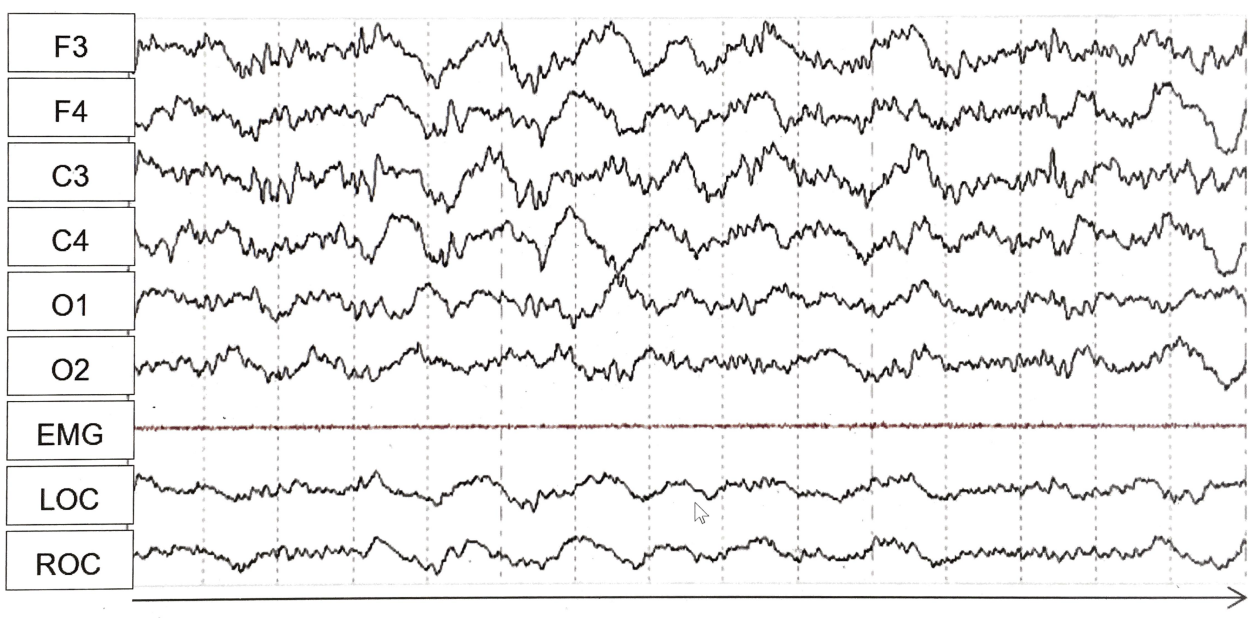

15 seconds

Figure I Electroencephalography tracing from an atypical sleep patient. F3, F4, C3, C4, OI, O2 indicate EEG lead locations. Abbreviations: EMG, electromyogram; LOC and ROC, left and right electrooculogram, respectively. 


\section{Sleep Stage}

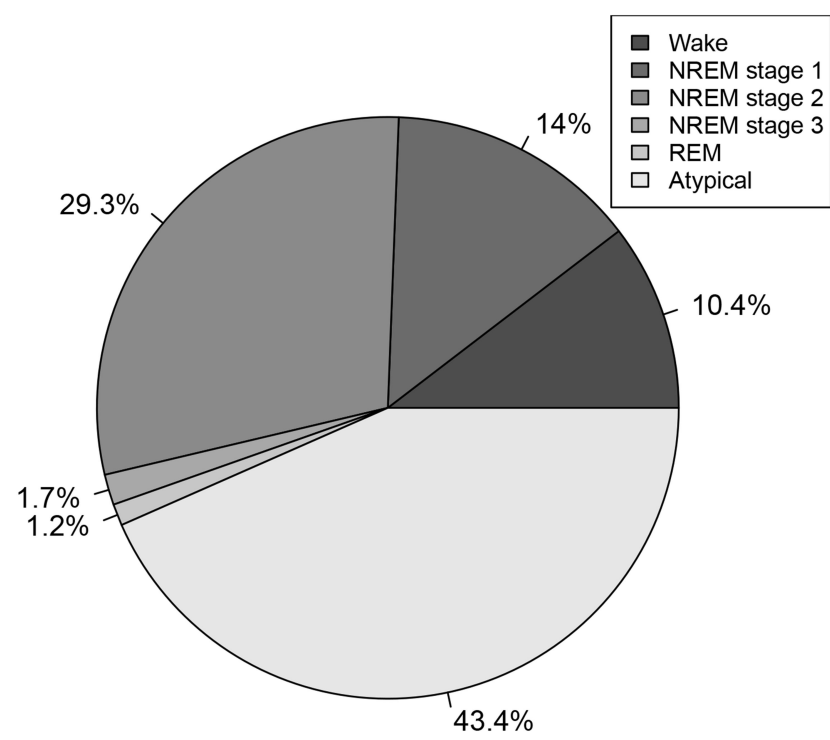

Figure 2 Sleep stage distribution in CSICU patients.

Abbreviations: NREM, non-rapid eye movement; REM, rapid eye movement.

Patients with delirium had decreased delta power $(P=$ $0.010)$ and percentage REM sleep $(P=0.011)$ and a higher incidence of atypical sleep $(P=0.005)$ and REM sleep absence $(P=0.028)$ (Table 3$)$.

\section{Discussion}

To our knowledge, this is the first study assessing the association between atypical sleep and delirium using

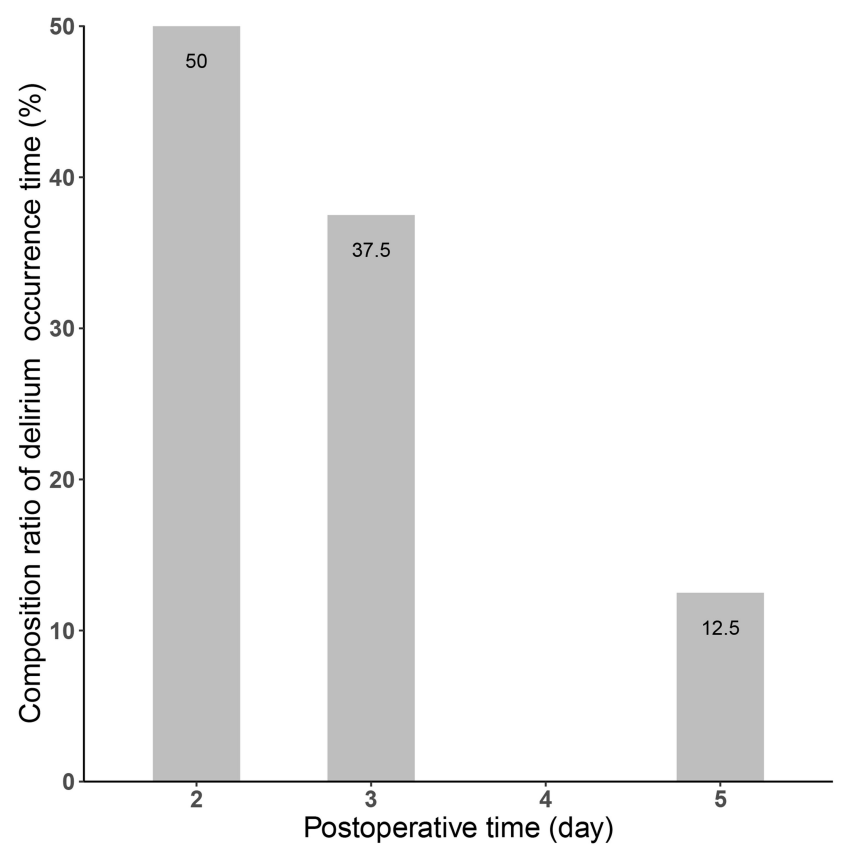

Figure 3 Composition ratio of postoperative delirium in different periods of CSICU patients.
PSG through prospectively collected sleep data before delirium onset. Overall, (1) sleep quality was generally poor among all CSICU patients; (2) $45.0 \%$ patients (9/ 20) developed atypical sleep on the first night after cardiac surgery; (3) and patients with delirium had decreased delta power and percentage REM sleep and a higher proportion of atypical sleep and REM sleep absence.

According to the Principles and Practice of Sleep Medicine (Version 6, 2017), ${ }^{24}$ stage N1, N2, N3, and REM sleep generally constitute about 2\%-5\%, 45\%-55\%, $13 \%-23 \%$, and $20-25 \%$ of sleep. However, sleep in CSICU patients is often altered because of the influence of various factors, such as pain, dyspnea, sleep-affecting drugs, ICU environment, and so forth. ${ }^{25}$ A study by Orr analyzed sleep in 6 patients undergoing open-heart surgery and found that only 1 patient showed electrophysiologic evidence of stage $\mathrm{N} 2$ sleep until the 2nd postoperative night, and 5 patients showed a total absence of REM sleep until the 4 th postoperative night. ${ }^{26}$ In another study of 38 patients undergoing coronary artery bypass grafting, the total sleep time reduced to $253.6 \pm 94.1 \mathrm{~min}$, with suppressed stage N3 sleep and REM sleep. ${ }^{27}$ Trends among our data are generally consistent with results of the aforementioned studies, including decreased total sleep time, lower sleep efficiency, and suppressed stage N3 and REM sleep (Table 1).

Severe REM sleep reduction $(<6 \%$ of total sleep time) is associated with delirium. ${ }^{28}$ A study by Evans $^{29}$ including patients undergoing artificial hip replacement showed that reduced total sleep time and reduced non-REM delta power on the 2 nd night postoperatively are related to greater POD severity. Similarly, in this study, we found that reduced delta power and absence of REM sleep are associated with POD. Animal studies have shown that REM sleep deprivation cause neurotransmitters imbalance, including increased acetylcholinesterase activity (responsible for acetylcholine degradation) and dopamine levels. $^{30,31}$ Neurotransmitter imbalance (particularly decreased acetylcholine level and increased dopamine level) plays a key role in the development of delirium. ${ }^{32}$ In contrast, we did not find any statistically significant association between total sleep time and POD. Our inclusion of critically ill patients undergoing cardiac surgery with $\mathrm{CPB}$ in this study could explain this difference. Several studies have reported on cardiac surgery affecting sleep characteristics. ${ }^{25}$ Moreover, sleep in the CSICU is disturbed more often 
Table 2 Baseline Characteristics in Non-Delirium Group vs. Delirium Group

\begin{tabular}{|c|c|c|c|c|}
\hline & Non-Delirium $(n=\mid 2)$ & Delirium $(n=8)$ & $t / z / x^{2}$ & $\mathbf{P}$ \\
\hline \multicolumn{5}{|l|}{ Sociodemographic characteristics } \\
\hline Age $(y)$, mean $(S D)$ & $53.25 \pm 15.09$ & $49.38 \pm 12.66$ & 0.598 & $0.557^{\dagger}$ \\
\hline Male, n (\%) & $6(50.0)$ & $5(62.5)$ & - & $0.670^{\xi}$ \\
\hline BMI $\left(\mathrm{kg} / \mathrm{m}^{2}\right)$, mean $(\mathrm{SD})$ & $23.90 \pm 4.23$ & $26.52 \pm 7.42$ & -0.855 & $0.408^{\dagger}$ \\
\hline Married, n (\%) & II (91.7) & $8(100.0)$ & - & $>0.999 \xi$ \\
\hline Education level, $n(\%)$ & & & 1.235 & $0.539^{\ddagger}$ \\
\hline Primary school and below & $5(4 I .7)$ & $2(25.0)$ & & \\
\hline Junior and senior high school & $5(41.7)$ & $3(37.5)$ & & \\
\hline College and above & $2(16.7)$ & $3(37.5)$ & & \\
\hline Smoker, n (\%) & $6(50.0)$ & $2(25.0)$ & - & $0.373^{\xi}$ \\
\hline Drinker, n (\%) & $0(0)$ & I (I2.5) & - & $0.400^{\xi}$ \\
\hline \multicolumn{5}{|l|}{ Preoperative } \\
\hline Hypertension, n (\%) & $5(41.7)$ & $7(87.5)$ & - & $0.070^{\xi}$ \\
\hline Diabetes, n (\%) & I (8.3) & $0(0)$ & - & $>0.999^{\xi}$ \\
\hline Cerebrovascular disease, n (\%) & $0(0)$ & I (I2.5) & - & $0.400^{\xi}$ \\
\hline Sedation use, $n(\%)$ & $0(0)$ & I (I2.5) & - & $0.400^{\xi}$ \\
\hline Analgesia use, n (\%) & $8(66.7)$ & $6(75.0)$ & - & $>0.999^{\xi}$ \\
\hline LVEF (\%), mean (SD) & $63.3 \pm 6.7$ & $63.5 \pm 6.0$ & -0.086 & $0.932^{\dagger}$ \\
\hline \multicolumn{5}{|l|}{ Intraoperative } \\
\hline Operating time $(\min )$, mean (SD) & $282.58 \pm 58.25$ & $312.38 \pm 129.94$ & -0.609 & $0.558^{\dagger}$ \\
\hline CPB time (min), mean (SD) & $145.91 \pm 43.60$ & $|44.43 \pm 49.7|$ & 0.068 & $0.946^{\dagger}$ \\
\hline Aortic cross-clamp time (min), mean (SD) & $71.83 \pm 28.78$ & $84.88 \pm 29.42$ & -0.984 & $0.338^{\dagger}$ \\
\hline \multicolumn{5}{|l|}{ Postoperative to the end of PSG } \\
\hline Sedation use, n (\%) & $3(25.0)$ & $0(0)$ & - & $0.242^{\xi}$ \\
\hline Analgesia use, $\mathrm{n}(\%)$ & $4(33.3)$ & $3(37.5)$ & - & $>0.999^{\xi}$ \\
\hline APACHE-II score, mean (SD) & $28.27 \pm 6.65$ & $28.75 \pm 2.66$ & -0.216 & $0.832^{\dagger}$ \\
\hline Length of MV (h), median (IQR) & $25.0(19.0,148.0)$ & $45.5(20.3,98.3)$ & -0.133 & $0.894^{*}$ \\
\hline Length of ICU stays (d), median (IQR) & $5.5(3.3,14.8)$ & $5.5(3.0,9.8)$ & -0.428 & $0.668^{*}$ \\
\hline
\end{tabular}

Notes: ${ }^{\dagger}$ Student's $t$-test; ${ }^{* M a n n}-$ Whitney $U$-test; ${ }^{\ddagger}$ Chi-square test; ${ }^{\xi}$ Fisher's Exact Test.

Abbreviations: BMI, body mass index; LEVF, left ventricular ejection fraction; CPB, cardiopulmonary bypass; APACHE, acute physiology and chronic health evaluation; MV, mechanical ventilation; ICU, intensive care unit; SD, standard deviation; IQR, interquartile range.

because of the lights, noise, and a high frequency of medical and nursing activities than in the general ward.

The concept of atypical sleep was introduced by Cooper in 2012, and it is prevalent among ICU patients. ${ }^{10} \mathrm{~A}$ study verifying the feasibility of unattended PSG indicated that $44 \%$ of the patients with atypical sleep had delirium compared to $18 \%$ of patients with normal sleep; however, this study could not conclusively establish whether atypical sleep occurs before delirium onset, and the association was not statistically significant. ${ }^{11}$ The results of our study showed that atypical sleep that occurred before POD is associated with POD. K-complexes and sleep spindle loss are key characteristics of atypical sleep. Higher spindle density has been shown to predict better performance with regard to verbal ability and attention; this indicates 
Table 3 Sleep Characteristics in Non-Delirium Group vs. Delirium Group

\begin{tabular}{|c|c|c|c|c|}
\hline & Non-Delirium $(n=\mid 2)$ & Delirium $(n=8)$ & $t / z$ & $\mathbf{P}$ \\
\hline Total recording time $(\mathrm{min})$, mean (SD) & $492.93 \pm 59.15$ & $526.65 \pm 44.35$ & -1.371 & $0.187^{\dagger}$ \\
\hline Total sleep time (min), mean (SD) & $260.80 \pm 83.40$ & $197.85 \pm 71.72$ & 1.744 & $0.098^{\dagger}$ \\
\hline Sleep efficiency (\%), mean (SD) & $54.1 \pm 18.9$ & $38.0 \pm 14.1$ & 2.048 & $0.055^{\dagger}$ \\
\hline Stage NI sleep (\%), mean (SD) & $13.4 \pm 6.3$ & $15.1 \pm 9.0$ & -0.508 & $0.618^{\dagger}$ \\
\hline Stage N2 sleep (\%), mean (SD) & $34.1 \pm 23.1$ & $22.2 \pm 13.7$ & 1.306 & $0.208^{\dagger}$ \\
\hline Stage N3 sleep (\%), median (IQR) & $1.3(0,3.8)$ & $0(0,2.7)$ & -1.435 & $0.15 I^{*}$ \\
\hline REM sleep (\%), median (IQR) & $2.1(0,3.2)$ & $0(0,0.5)$ & -2.535 & $0.011 *$ \\
\hline Delta $\left(\mu \mathrm{V}^{2}\right)$, median (IQR) & $22,866.60(10,191.84,36,892.07)$ & $6431.76(4861.79,10,907.65)$ & -2.582 & $0.010^{*}$ \\
\hline Theta $\left(\mu V^{2}\right)$, mean $(S D)$ & $4585.63 \pm 2626.11$ & $2894.31 \pm \mid 873.58$ & 1.377 & $0.206^{\dagger}$ \\
\hline Alpha $\left(\mu \mathrm{V}^{2}\right)$, mean $(\mathrm{SD})$ & $1|98.9| \pm 726.27$ & ||$|2| .87 \pm 687.34$ & 0.201 & $0.844^{\dagger}$ \\
\hline Beta $\left(\mu \mathrm{V}^{2}\right)$, mean $(\mathrm{SD})$ & $165.50 \pm 115.65$ & $196.48 \pm 107.35$ & -0.511 & $0.619^{\dagger}$ \\
\hline Absence of stage N3 sleep, n (\%) & $3(25.0)$ & $5(62.5)$ & - & $0.167^{\xi}$ \\
\hline Absence of REM sleep, $n(\%)$ & $4(33.3)$ & $7(87.5)$ & - & $0.028^{8}$ \\
\hline Atypical sleep, n (\%) & $2(16.7)$ & $7(87.5)$ & - & $0.005^{\xi}$ \\
\hline
\end{tabular}

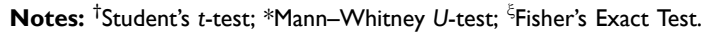

Abbreviations: REM, rapid eye movement; SD, standard deviation; IQR, interquartile range.

the potential utility of sleep spindles as markers of cognitive functioning. ${ }^{33,34}$ Regarding K-complexes, studies have associated these not only with sleep maintenance but also with executive function. ${ }^{35}$ Clinical studies have confirmed that worse cognitive performance is an important trigger for delirium. ${ }^{36-38}$ Therefore, we speculate that the association between atypical sleep and POD may be linked to acute impairment in cognitive function caused by K-complex and sleep spindles loss.

\section{Study Limitations}

The main limitation of this study is its small sample size that, precluded establishing atypical sleep as an independent risk factor of POD. Some patients underwent emergency surgery such as aortic dissection surgery. Thus, we could not obtain preoperative PSG data of all patients. Preoperative sleep disturbance is a potential risk factor for POD. ${ }^{39}$ In our study, although we excluded patients with high-risk sleep disturbance (STOP-Bang score $\geq 3$ ) and gathered detailed history of sleep-related disease, all patients with preoperative sleep disturbance could not be excluded. Furthermore, we did not assess daytime sleep characteristics. However, a long-term (24 h) PSG study among ICU patients found that sleep architecture and quality were generally similar between the day and night. ${ }^{10}$ Thus, we believe that nighttime studies were sufficient for characterizing the sleep patterns of our patients.

\section{Conclusion}

According to our results, atypical sleep and no REM sleep on the first postoperative night are associated with POD. Further large-scale studies are needed to validate these results.

\section{Ethics Approval and Informed Consent}

All procedures performed in this study were in accordance with the ethical standards of the Union Hospital, Fujian Medical University and with the 1964 Helsinki declaration and its later amendments or comparable ethical standards. Informed consent was obtained from all individual participants included in the study.

\section{Acknowledgments}

The authors thank the Department of Neurology and Sleep Medicine of Fujian Medical University Union Hospital for providing PSG technical support and the Heart Medicine Research Center of Fujian Medical University Union Hospital for providing study site. Yanjuan Lin and LiangWan Chen are co-corresponding authors.

\section{Funding}

This work was supported by the Joint Finds for the Innovation of Science and Technology, Fujian province (Grant number: 2017Y9052) and the Guiding Project of Fujian Science and Technology (2017Y0038). 


\section{Disclosure}

The authors report no conflicts of interest in this work.

\section{References}

1. Järvelä K, Porkkala H, Karlsson S, Martikainen T, Selander T, Bendel S. Postoperative delirium in cardiac surgery patients. J Cardiothorac Vasc Anesth. 2018;32(4):1597-1602. doi:10.1053/j. jvca.2017.12.030

2. Cereghetti C, Siegemund M, Schaedelin S, et al. Independent predictors of the duration and overall burden of postoperative delirium after cardiac surgery in adults: an Observational Cohort Study. J Cardiothorac Vasc Anesth. 2017;31(6):1966-1973. doi:10.1053/j. jvca.2017.03.042

3. Thomason JW, Shintani A, Peterson JF, Pun BT, Jackson JC, Ely EW. Intensive care unit delirium is an independent predictor of longer hospital stay: a prospective analysis of 261 non-ventilated patients. Crit Care. 2005;9(4):R375-R381. doi:10.1186/cc3729

4. Vasilevskis EE, Chandrasekhar R, Holtze $\mathrm{CH}$, et al. The cost of ICU delirium and coma in the intensive care unit patient. Med Care. 2018;56(10):890-897. doi:10.1097/MLR.0000000000000975

5. Ely EW, Shintani A, Truman B, et al. Delirium as a predictor of mortality in mechanically ventilated patients in the intensive care unit. JAMA. 2004;291(14):1753-1762. doi:10.1001/jama.291.14. 1753

6. Thorsteinsdóttir SA, Sveinsdóttir H, Snædal J. Delirium after open cardiac surgery: systematic review of prevalence, risk factors and consequences. Laeknabladid. 2015;101(6):305-311.

7. Gosselt AN, Slooter AJ, Boere PR, Zaal IJ. Risk factors for delirium after on-pump cardiac surgery: a systematic review. Crit Care. 2015;19:346. doi:10.1186/s13054-015-1060-0

8. Weinhouse GL, Schwab RJ, Watson PL, et al. Bench-to-bedside review: delirium in ICU patients - importance of sleep deprivation. Crit Care. 2009;13(6):234. doi:10.1186/cc8131

9. Iber C, Ancoli-Israel S, Chesson AL, Quan S. The AASM Manual for the Scoring of Sleep and Associated Events: Rules, Terminology and Technical Specifications. Westchester, IL: American Academy of Sleep Medicine; 2007.

10. Cooper AB, Thornley KS, Young GB, Slutsky AS, Stewart TE, Hanly PJ. Sleep in critically ill patients requiring mechanical ventilation. Chest. 2000;117(3):809-818. doi:10.1378/chest. 117.3.809

11. Knauert MP, Yaggi HK, Redeker NS, Murphy TE, Araujo KL, Pisani MA. Feasibility study of unattended polysomnography in medical intensive care unit patients. Heart Lung. 2014;43 (5):445-452.

12. Thille AW, Reynaud F, Marie D, et al. Impact of sleep alterations on weaning duration in mechanically ventilated patients: a prospective study. Eur Respir J. 2018;51(4).

13. Drouot X, Roche-Campo F, Thille AW, et al. A new classification for sleep analysis in critically ill patients. Sleep Med. 2012;13(1):7-14. doi:10.1016/j.sleep.2011.07.012

14. Roche Campo F, Drouot X, Thille AW, et al. Poor sleep quality is associated with late noninvasive ventilation failure in patients with acute hypercapnic respiratory failure. Crit Care Med. 2010;38 (2):477-485.

15. Watson PL, Pandharipande P, Gehlbach BK, et al. Atypical sleep in ventilated patients: empirical electroencephalography findings and the path toward revised ICU sleep scoring criteria. Crit Care Med. 2013;41(8):1958-1967.

16. Boesen HC, Andersen JH, Bendtsen AO, Jennum PJ. Sleep and delirium in unsedated patients in the intensive care unit. Acta Anaesthesiol Scand. 2016;60(1):59-68. doi:10.1111/aas.12582
17. Bradley KA, DeBenedetti AF, Volk RJ, Williams EC, Frank D, Kivlahan DR. AUDIT-C as a brief screen for alcohol misuse in primary care. Alcohol Clin Exp Res. 2007;31(7):1208-1217.

18. Chung F, Yegneswaran B, Liao P, et al. STOP questionnaire: a tool to screen patients for obstructive sleep apnea. Anesthesiology. 2008;108 (5):812-821.

19. Ely EW, Margolin R, Francis J, et al. Evaluation of delirium in critically ill patients: validation of the Confusion Assessment Method for the Intensive Care Unit (CAM-ICU). Crit Care Med. 2001;29(7):1370-1379. doi:10.1097/00003246-200107000-00012

20. Sessler CN, Gosnell MS, Grap MJ, et al. The richmond agitation-sedation scale: validity and reliability in adult intensive care unit patients. Am J Respir Crit Care Med. 2002;166 (10):1338-1344.

21. Shadvar K, Baastani F, Mahmoodpoor A, Bilehjani E. Evaluation of the prevalence and risk factors of delirium in cardiac surgery ICU. J Nurs Res. 2013;5(4):157-161.

22. Swart LM, van der Zanden V, Spies PE, de Rooij SE, van Munster BC. The comparative risk of delirium with different opioids: a systematic review. Drugs Aging. 2017;34(6):437-443. doi:10.1007/ s40266-017-0455-9

23. Skrobik Y, Duprey MS, Hill NS, Devlin JW. Low-dose nocturnal dexmedetomidine prevents ICU delirium. a randomized, placebo-controlled trial. Am J Respir Crit Care Med. 2018;197 (9):1147-1156. doi:10.1164/rccm.201710-1995OC

24. Kryger MH, Roth T, Dement WC. Principles and Practice of Sleep Medicine. 6th ed. Philadelphia, PA: Elsevier; 2017.

25. Liao W-C, Huang C-Y, Huang T-Y, Hwang S-L. A systematic review of sleep patterns and factors that disturb sleep after heart surgery. J Nurs Res. 2011;19(4):275-288.

26. Orr WC, Stahl ML. Sleep disturbances after open heart surgery. $A m$ J Cardiol. 1977;39(2):196-201. doi:10.1016/S0002-9149(77)80191-4

27. Edéll-Gustafsson UM, Hetta JE, Arén CB. Sleep and quality of life assessment in patients undergoing coronary artery bypass grafting. $J A d v$ Nurs. 1999;29(5):1213-1220. doi:10.1046/j.1365-2648.1999.01006.x

28. Trompeo AC, Vidi Y, Locane MD, et al. Sleep disturbances in the critically ill patients: role of delirium and sedative agents. Minerva Anestesiol. 2011;77(6):604-612.

29. Evans JL, Nadler JW, Preud'homme XA, et al. Pilot prospective study of post-surgery sleep and EEG predictors of post-operative delirium. Clin Neurophysiol. 2017;128(8):1421-1425. doi:10.1016/j. clinph.2017.05.004

30. Siddique SA, Tamilselvan T, Vishnupriya M, Balamurugan E. Evaluation of neurotransmitter alterations in four distinct brain regions after Rapid Eye Movement Sleep Deprivation (REMSD) induced mania-like behaviour in Swiss Albino Mice. Neurochem Res. 2018;43(6):1171-1181. doi:10.1007/s11064-018-2533-8

31. Benedito MA, Camarini R. Rapid eye movement sleep deprivation induces an increase in acetylcholinesterase activity in discrete rat brain regions. Braz J Med Biol Res. 2001;34(1):103-109.

32. Wang Y, Shen X. Postoperative delirium in the elderly: the potential neuropathogenesis. Aging Clin Exp Res. 2018;30(11):1287-1295. doi:10.1007/s40520-018-1008-8

33. Lafortune M, Gagnon J-F, Martin N, et al. Sleep spindles and rapid eye movement sleep as predictors of next morning cognitive performance in healthy middle-aged and older participants. J Sleep Res. 2014;23(2):159-167. doi:10.1111/jsr.12108

34. Schilling C, Schlipf M, Spietzack S, et al. Fast sleep spindle reduction in schizophrenia and healthy first-degree relatives: association with impaired cognitive function and potential intermediate phenotype. Eur Arch Psychiatry Clin Neurosci. 2017;267 (3):213-224. doi:10.1007/s00406-016-0725-2

35. Ramakrishnan M, Sartory G, van Beekum A, Lohrmann T, Pietrowsky R. Sleep-related cognitive function and the K-complex in schizophrenia. Behav Brain Res. 2012;234(2):161-166. doi:10.1016/j.bbr.2012.06.019 
36. Koskderelioglu A, Onder O, Gucuyener M, Altay T, Kayali C, Gedizlioglu M. Screening for postoperative delirium in patients with acute hip fracture: assessment of predictive factors. Geriatr Gerontol Int. 2017;17(6):919-924.

37. Miao S, Shen P, Zhang Q, et al. Neopterin and mini-mental state examination scores, two independent risk factors for postoperative delirium in elderly patients with open abdominal surgery. $J$ Cancer Res Ther. 2018;14(6):1234-1238.
38. Shin JE, Kyeong S, Lee JS, et al. A personality trait contributes to the occurrence of postoperative delirium: a prospective study. $B M C$ Psychiatry. 2016;16(1):371. doi:10.1186/s12888-016-1079-z

39. Fadayomi AB, Ibala R, Bilotta F, Westover MB, Akeju O. A systematic review and meta-analysis examining the impact of sleep disturbance on postoperative delirium. Crit Care Med. 2018;46(12):e1204-e1212. doi:10.1097/CCM.0000000000003400

\section{Publish your work in this journal}

Nature and Science of Sleep is an international, peer-reviewed, open access journal covering all aspects of sleep science and sleep medicine, including the neurophysiology and functions of sleep, the genetics of sleep, sleep and society, biological rhythms, dreaming, sleep disorders and therapy, and strategies to optimize healthy sleep.
The manuscript management system is completely online and includes a very quick and fair peer-review system, which is all easy to use. Visit http://www.dovepress.com/testimonials.php to read real quotes from published authors. 